\title{
Mechanism, Cause, and Control of Water, Solutes, and Gas Migration Triggered by Mining Activities
}

\author{
Fangtian Wang $\mathbb{D},{ }^{1}$ Wen Wang $\mathbb{D},{ }^{2}$ Bisheng Wu $\left(\mathbb{D},{ }^{3}\right.$ Qingsheng Bai $\mathbb{D},{ }^{1,4}$ \\ and Mandadige S. A. Perera ${ }^{5}$ \\ ${ }^{1}$ School of Mines, State Key Laboratory of Coal Resources and Safe Mining, Key Laboratory of Deep Coal Resource Mining, \\ Ministry of Education of China, China University of Mining and Technology, Xuzhou, Jiangsu 221116, China \\ ${ }^{2}$ School of Energy Science Engineering, Henan Polytechnic University, Jiaozuo 454003, China \\ ${ }^{3}$ State Key Laboratory of Hydroscience and Engineering, Department of Hydraulic Engineering, Tsinghua University, \\ Beijing 100084, China \\ ${ }^{4}$ University of Toronto, Toronto, Canada \\ ${ }^{5}$ Department of Infrastructure Engineering, University of Melbourne, Melbourne, Australia \\ Correspondence should be addressed to Fangtian Wang; wangfangtian111@cumt.edu.cn
}

Received 29 January 2019; Accepted 29 January 2019; Published 21 April 2019

Copyright ( 2019 Fangtian Wang et al. This is an open access article distributed under the Creative Commons Attribution License, which permits unrestricted use, distribution, and reproduction in any medium, provided the original work is properly cited.

\section{Motivation and Background}

Although the growth in global coal consumption has been sharply slowed with the falls in China offset to a greater extent by the increasing demand in India and other emerging Asian countries, coal still remains the largest source of energy for the world with a share of almost $30 \%$ by 2040 [1]. Mining industry plays an important role in extracting underground resources, including coal [2]. However, a large number of disastrous mine accidents, such as flood, water inrush, tunnel collapse, gas outburst, and gas explosion, have been reported due to water and gas migration caused by the mining activities, posing a threat to the environment and also to the health and safety of field workers [3-5]. According to incomplete statistics, mining-induced accidents kill over thousands of workers around the world every year, especially in developing countries such as China and India. Water inrush and gas explosion accidents are the major causes for the reported mine accidents $[6,7]$.

In addition, mining activity may cause potential environmental issues [8-10], such as underground mine water, coal mine methane, ground subsidence, and acid mine drainage. Among them, underground mining lowers the water level and changes the flow of groundwater. Most of underground water is pumped out to the ground and only a small percentage of this water is reused. Removing so much water creates a kind of funnel that drains groundwater from the surrounding mining site. Secondly, coal mining releases a large amount of methane into the atmosphere, contributing about $6 \%$ of the global methane emission. Methane is 22 times as powerful as carbon dioxide and thus has the ability to disrupt the climate over a 20-year timespan. Ground subsidence occurs with the collapsing of earth into underground mines and has been a serious issue. In longwall mining faces, columns of coal are used to support the overlying strata. When the coal is extracted from the underground, the land above the mine site starts to sink, potentially damaging the buildings and entire landscapes. Subsidence may also cause farmland to become wetland or lakes by filling them with water. Finally, acid or neutral mine drainage may occur when coal and other rocks mix with water during mining. The water with high percentages of toxic minerals and heavy metals leaks out of abandoned mines, thus contaminating the groundwater, soil, and plants. Therefore, it is very important to have a sound understanding of the mechanisms of these hazards, which are reflected by the rock and fluid behaviors during mining.

The migration of water and gas through rocks during mining is a complex problem which may involve multiphase 
(solid, liquid, and gas), multiscale (nano to macro), and multifield-coupled (mechanical, thermal, chemical, hydro, etc.) processes. Understanding of this may also require a sound knowledge on biogeochemically sustained processes, such as production of acid drainages. Related phase changes, which may cause rock damage or crack propagation, further complicate the problem. As there are many factors affecting this coupled process, the mechanism behind the water and gas migration and rock deformation has still not been completely understood and thus needs to be further investigated so that proper measures can be taken to prevent mining-induced hazards. In addition, effective controlling technologies, such as underground reservoir, waterpreserved mining, integrated coal mining and gas extraction technologies, and effective hydraulic fracturing technologies, are encouraged to be further explored for a safer and more environment-friendly mining.

\section{Contents of the Special Issue}

This special issue has received in total 69 high-quality original research articles and review papers on the advances in the mechanisms, causes, and control technologies related to clean and contaminated water/gas migrations triggered by mining activities. Most of them are based on the numerical and theoretical simulations and laboratory experiments; a few case studies from the field work have also been involved. This special issue covers a wide range of topics, including underground mining induced rock fracture/damage, underground water mitigation, water inrush prevention, coal pillar dam stability, coalmine methane and enhanced gas recovery, shale gas reservoir, ground subsidence, and natural gas hydrate.

The first topic is on hydraulic properties of rock mass and the associated water and methane mitigations. D. Ma et al. presented an experimental study on the effect of sandstone and mudstone particle weight ratio on the non-Darcy hydraulic properties in their paper titled "Experimental Investigation on Hydraulic Properties of Granular Sandstone and Mudstone Mixtures." In the paper "Shear-Induced Permeability Evolution of Sandstone Fractures," H. Zhang et al. presented the triaxial shear test on saw-cut sandstone fractures with different types of surface roughness to improve the understanding of shear-slip-induced permeability characteristics. The results indicated that the permeabilitydisplacement curves can be divided into three stages, i.e., a stable stage, a stage with permeability decreasing, and a second stable stage, which exhibit similar behavior as the shear stress-displacement curves. Roughness changes before and after the shear tests had been used to examine the mechanism (e.g., surface grinding and sealing) behind the observed permeability reduction. In the paper "Numerical Simulation of Shear Behavior and Permeability Evolution of Rock Joints with Variable Roughness and Infilling Thickness" based on a DEM numerical modeling by J. Cheng et al., it is found that the permeability of infilled rock joints increases with both the thickness ratio (ratio of infill thickness to rock height) and joint roughness coefficient (JRC) during joint shearing. In the paper titled "Experimental Study on the Permeability of
Weakly Cemented Rock under Different Stress States in Triaxial Compression Tests," G. Fan et al. conducted a series of triaxial seepage experiments on weakly cemented mudstone and coarse sandstone collected from the Jurassic area in Northwestern China. For mudstone, permeability decreases in the elastic stage and then rapidly increases to the maximum at the end of the yield stage, followed by a slight decrease at the residual stage. The permeability ranges from $10^{-17}$ to $10^{-19} \mathrm{~m}^{2}$, representing a stable water-resisting property. Mudstone's permeability is 1 to 2 orders of magnitude lower than that of coarse sandstone. The scanning electron microscope (SEM) and X-ray diffraction analysis show that the seepage property is closely related with the rocks' microstructure and composition. In the paper "Multicomponent Lattice Boltzmann Simulations of Gas Transport in a Coal Reservoir with Dynamic Adsorption”, Z. Peng et al. proposed a double distribution Lattice Boltzmann model to analyze the gas-solid dynamic adsorption process for multicomponent gas migration in the unconventional reservoir. The results show that the adsorption becomes stronger when the specific surface area and the fracture porosity increase and the matrix size decreases. The effect of saturation adsorption amount has shown an opposite trend, where adsorption rate increases with the difference between saturation adsorption capacity and the adsorbed amount, and the impact of Langmuir pressure shows a similar trend as the fracture porosity. C. Zhang et al. has developed a large-scale gas seepage model to simulate the gas emission during the process of upper protective coal seam mining in their paper titled "A Gas Seepage Modeling Study for Mitigating Gas Accumulation Risk in Upper Protective Coal Seam Mining Process". In the paper titled "The Migration of Coalbed Methane under Mining Pressure and Air Injection: A Case study in China," L. Zhang et al. proposed a dual-porosity and dual-permeability methane drainage model to analyze the effect of mining pressure on the methane extraction from coal seams. Numerical simulation has also been extended to understand the effect of a field practice. Both methods show that mining-induced fractures increase the permeability of coal and promote the pressure drops in the nearby coal matrix, thus eliminating the danger of gas outbursts. In the paper titled "Time Characteristics of the Influence Radius by Injecting $\mathrm{N}_{2}$ to Displace Coalbed Methane: A Case Study", L. Chen et al. used field experiments and numerical simulations to summarize the reasonable separation between the injection and discharge boreholes. In this study, they proposed a method to determine the reasonable well separation by increasing the influence radius, where the well separation was found to be dependent on injection pressure.

The second topic is related to ground water mitigation mechanisms and water-preserved mining technologies. In the paper titled "Damage Characteristics and Mechanism of a Strong Water Inrush Disaster at the Wangjialing Coal Mine, Shanxi Province, China," F. Cui et al. reported a groundwater inrush accident that occurred in that mine. The inrush groundwater came from the upper abandoned excavations. Principles for preventing these accidents have been suggested. In the paper titled "Study on the Stability of the Coal Seam Floor above a Confined Aquifer Using the 
Structural System Reliability Method," H. Lu et al. has proposed a method to study the effect of random rock mechanical parameters and loads on the stability of the floor above confined aquifers. In this method, two failure modes of a water-resistant floor have been suggested and Monte Carlo method was employed to calculate the reliability probability of each failure mode. In the paper titled "Effect of Coal Mining on Springs in the Yushenfu Mining Area of China," written by L. Fan et al. based on the hydrological surveys conducted in between 1994 and 2015, the mechanism of spring evolution and ecological effects of domain evolution have been analyzed by combining groundwater monitoring and coal mining intensity evaluation. In the paper titled "Mine Flooding History of a Regional Below-Drainage Coalfield Dominated by Barrier Leakage (1970-2014)," J. J. Donovan and E. F. Perry have collected water level fluctuation data in a series of adjacent closed underground mines to present flooding history of mines and to identify critical events that determined how mine pools evolved in this case. Their study shows that the progress of mine flooding is influenced by mining history and design, closure time, barrier leakage condition, and geologic structure.

The third topic involves underground coal mining induced fractures and movement and the associated control technologies. In the paper titled "A General Review on Longwall Mining-Induced Fractures in Near-Face Regions,", Q. Bai and S. Tu summarize the current achievements in characterizing mining-induced fractures in near-face regions, e.g., coal wall, chain pillar, immediate roofs and top coal, and floors. Remarks are made on the current progress of fundamental problems and developments in the methodologies for characterizing of mining-induced fractures, such as field observations, small-scale laboratory tests, and physical and numerical modeling. Based on a comprehensive analysis, the advantages and disadvantages of each method have been discussed and the ideal conditions for applying each of these methods have been recommended. In the paper titled "ForceFracture Characteristics of the Roof above Goaf in a Steep Coal Seam: A Case Study of Xintie Coal Mine", H. Tu et al. have utilized small-deflection theory for elastic thin plates to estimate roof deformation under the loads from both the overlying strata and the support provided by the backfill goaf in a steep coal mining panel. The results showed that fractures will first develop in the upper sections of the frontal and rear walls of the face and the middle of the upper suspended roof due to tension or shearing and ultimately form an E-shaped pattern. In the paper titled "Calculation Method of Overburden Damage Height Based on Fracture Mechanics Analysis of Soft and Hard Rock Layers", L. Chen et al. have constructed a fracture model by considering a quantitative classification criterion to predict the mining-induced overburden damage height for a specific geological condition of soft and hard interaction stratum. The method has been verified by numerical simulation and field measurements. They found that tensile fractures are predominated in soft strata but with less counts and lower angles, and the calculation results are more accurate than those from the conventional methods without considering the soft strata. In the paper titled "Field Measurement and Mechanical Analysis of
Height of the Water Flowing Fracture Zone in Short-Wall Block Backfill Mining beneath the Aquifer: A Case Study in China," Y. Zhang et al. established a mechanical model based on the theory of elastic foundation beam and characteristics of short-wall block filling mining to predict the height of water flowing fracture zone under these specific conditions. Field observations have been used to validate the proposed method, highlighting that the prediction based on conventional methods usually produces unreasonable large values. In the paper titled "Surface Subsidence Control Mechanism and Effect Evaluation of Gangue-Backfilling Mining: A Case Study in China," H. Li and G. Guo conducted a physical modeling on solid backfilling longwall mining based on a real case study. According to the results, thermal expansion coefficients of overlying strata, the interlayer fracture, and the subsidence were smaller in backfilling mining compared with those from the traditional longwall mining, where the surface subsidence reduces by more than $85 \%$.

The forth topic focuses on coal measures failure, damages and fractures. In the paper titled "Damage and Failure Evolution Mechanism for Coal Pillar Dams Affected by Water Immersion in Underground Reservoirs," written by F. Wang et al., a numerical model was used to analyze the fracture development and seepage fields in coal pillar dams in underground goaf, which is a key portion for the protection and utilization of water resources. The results showed that strength degradation induced by water immersion plays a significant role in coal pillar stability. In the paper titled "Crack Initiation Characteristics of Gas-Containing Coal under Gas Pressures," Z. Yin et al. have investigated strength properties (uniaxial compressive and tensile strengths and fracture toughness) and failure modes of gas-containing coal. It was found that these three parameters decrease with increasing the initial gas pressure. Z. Xiong et al. analyzed the mechanical properties and the failure process of coal under uniaxial compressive and grading relaxation conditions in the paper titled "Uniaxial Compression Creep Relaxation and Grading of Coal Samples via Tests on the Progressive Failure Characteristics." The results showed that the strength and elastic modulus obtained from the staged relaxation tests are lower than those from the conventional tests. Relaxation tests usually produced complicated fractures, which exhibit evident lateral expansion, while conventional compressive tests produced tension-shear double-fractures. The paper titled "Influence of Flaw Inclination Angle on Unloading Responses of Brittle Rock in Deep Underground" written by $Z$. Chen et al. has numerically investigated the unloading response of intact and pre-flawed hard rocks. The results showed that the unloading failure strength, unloading damage thresholds and cracking characteristics are dependent on the inclination angle of the pre-flaws. The strength of preflawed specimen decreased by 5.5\%-20\% compared to those of the intact specimens in the same tests. Fractures development and failure modes have also been compared between the intact and defected rocks.

In addition to the work mentioned above, some other interesting papers can be found in the special issue. We believe this special issue will provide useful references for mining workers and researchers and scholars whose work 
involves water, solutes, and gas migration triggered by mining activity fields.

\title{
Conflicts of Interest
}

The editors declare that they have no conflicts of interest regarding the publication of this special issue.

\section{Acknowledgments}

The guest editors would like to thank all the authors in this issue as well as the reviewers who generously spent valuable time in providing high-quality reviews for the submitted manuscripts. The program was funded by the Fundamental Research Funds for the Central Universities (2018ZDPY05) and the Priority Academic Program Development of Jiangsu Higher Education Institutions.

\author{
Fangtian Wang \\ Wen Wang \\ Bisheng Wu \\ Qingsheng Bai \\ Mandadige S. A. Perera
}

\section{References}

[1] BP energy economics, BP Energy Outlook, 92-93, 2018, https:// www.bp.com.

[2] L. X. Wu, Y. J. Wang, E. J. Ding et al., "Thirdly study on digital mineserve for mine safety and intellimine with support from IoT," Journal of China Coal Society, vol. 37, no. 3, pp. 357365, 2012.

[3] M. G. Qian, J. L. Xu, and J. C. Wang, "Further on the sustainable mining of coal," Journal of China Coal Society, vol. 43, no. 1, pp. 1-13, 2018.

[4] Y. Liang, "Scientific conception of precision coal mining," Journal of China Coal Society, vol. 42, no. 1, pp. 1-7, 2017.

[5] F. Wang, T. Ren, S. Tu, F. Hungerford, and N. Aziz, "Implementation of underground longhole directional drilling technology for greenhouse gas mitigation in Chinese coal mines," International Journal of Greenhouse Gas Control, vol. 11, no. 6, pp. 290-303, 2012.

[6] W. Dong, "Analyzing the development status of Indian occupational safety and coal mine safety," China Coal, vol. 37, no. 7, pp. 117-120, 2011.

[7] Y. Q. Li and H. H. Huang, "Current status and trend of coal mine safety in world's main coal mining countries," China Safety Science Journal, vol. 20, no. 6, pp. 158-165, 2010.

[8] Greenpease International, "About coal mining impacts," Background, 2016, https://www.greenpeace.org/archiveinternational/en/campaigns/climate-change/coal/Coalmining-impacts/.

[9] D. Beamish and B. Klinck, "Hydrochemical characterization of a coal mine plume detected by an airborne geophysical survey," Geofluids, vol. 6, no. 1, p. 92, 2006.

[10] P. Huang and X. Wang, "Piper-PCA-Fisher recognition model of water inrush source: a case study of the Jiaozuo mining area," Geofluids, vol. 2018, Article ID 9205025, 10 pages, 2018. 

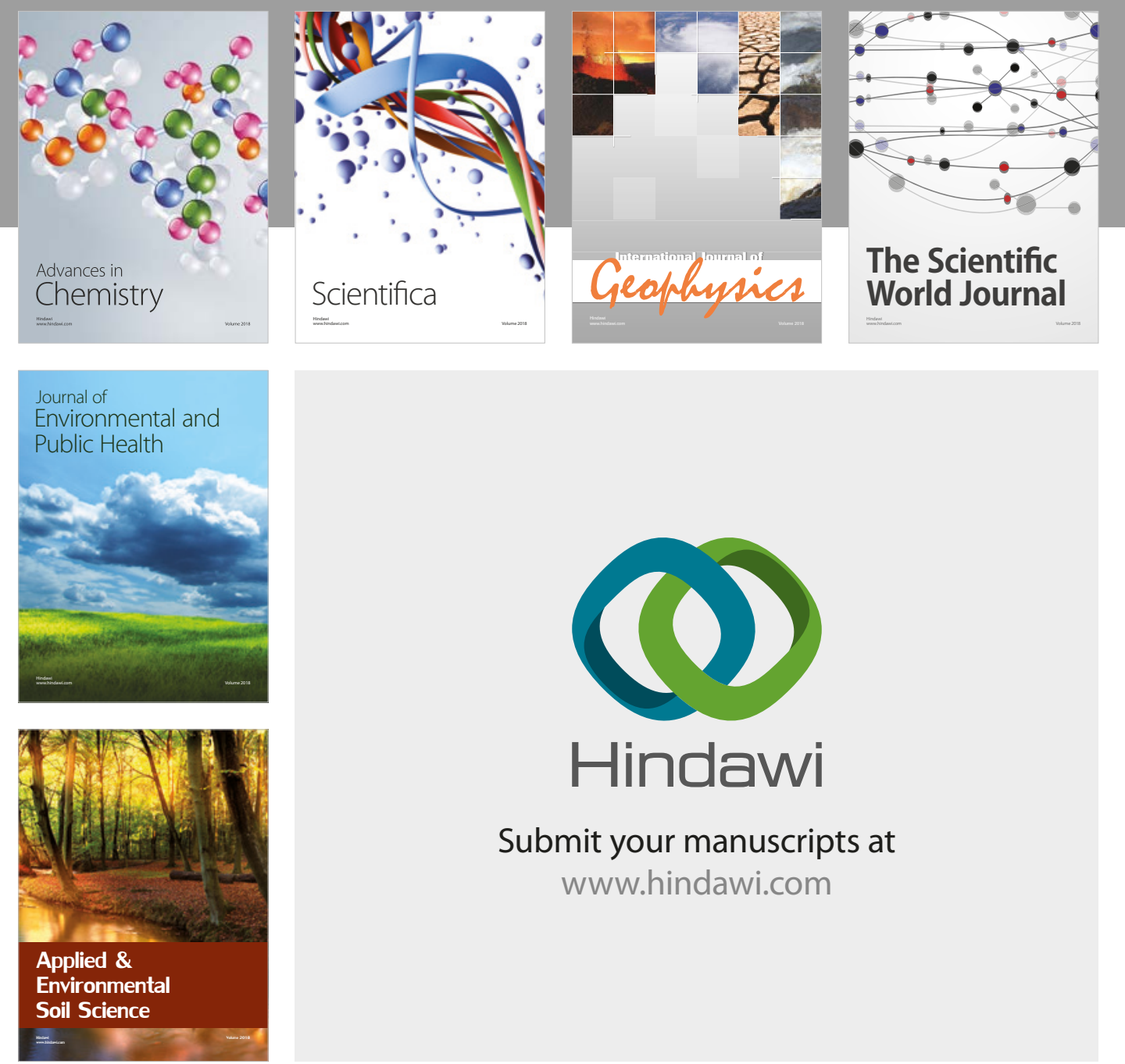

The Scientific

\section{World Journal}
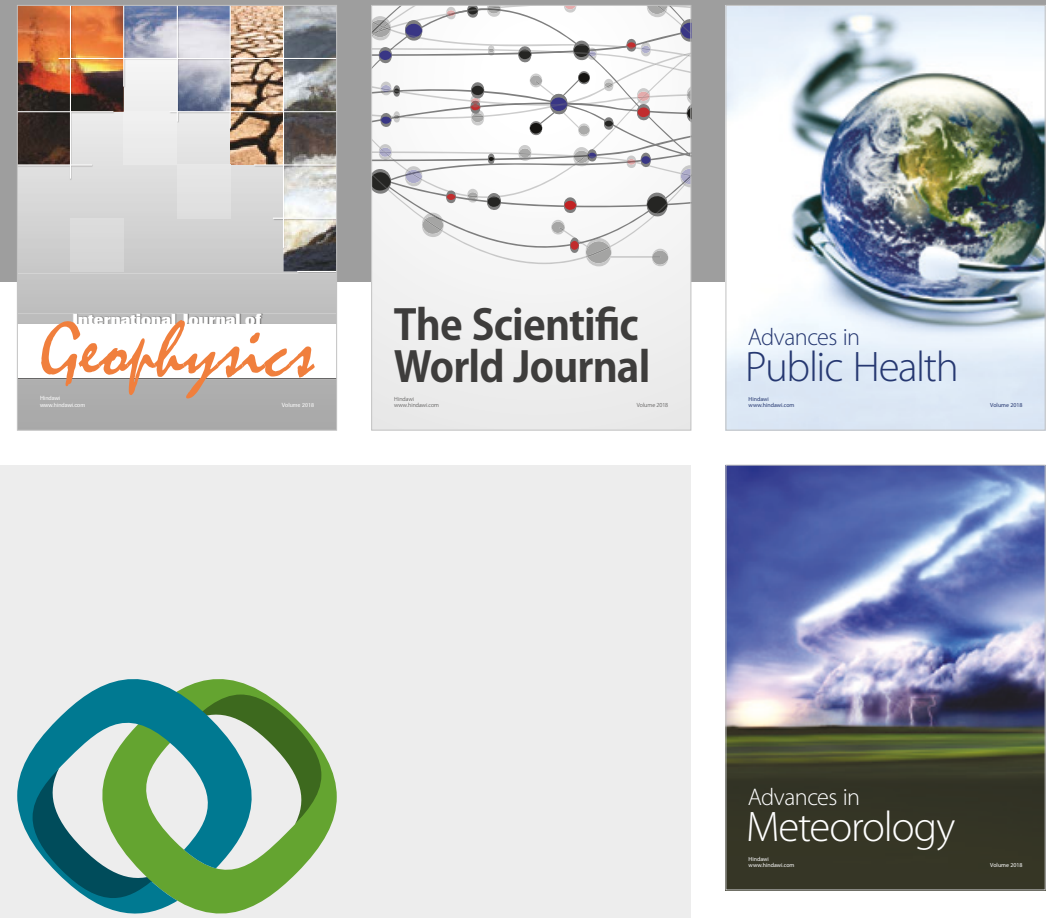

Advan

Public Health

\section{Hindawi}

Submit your manuscripts at

www.hindawi.com
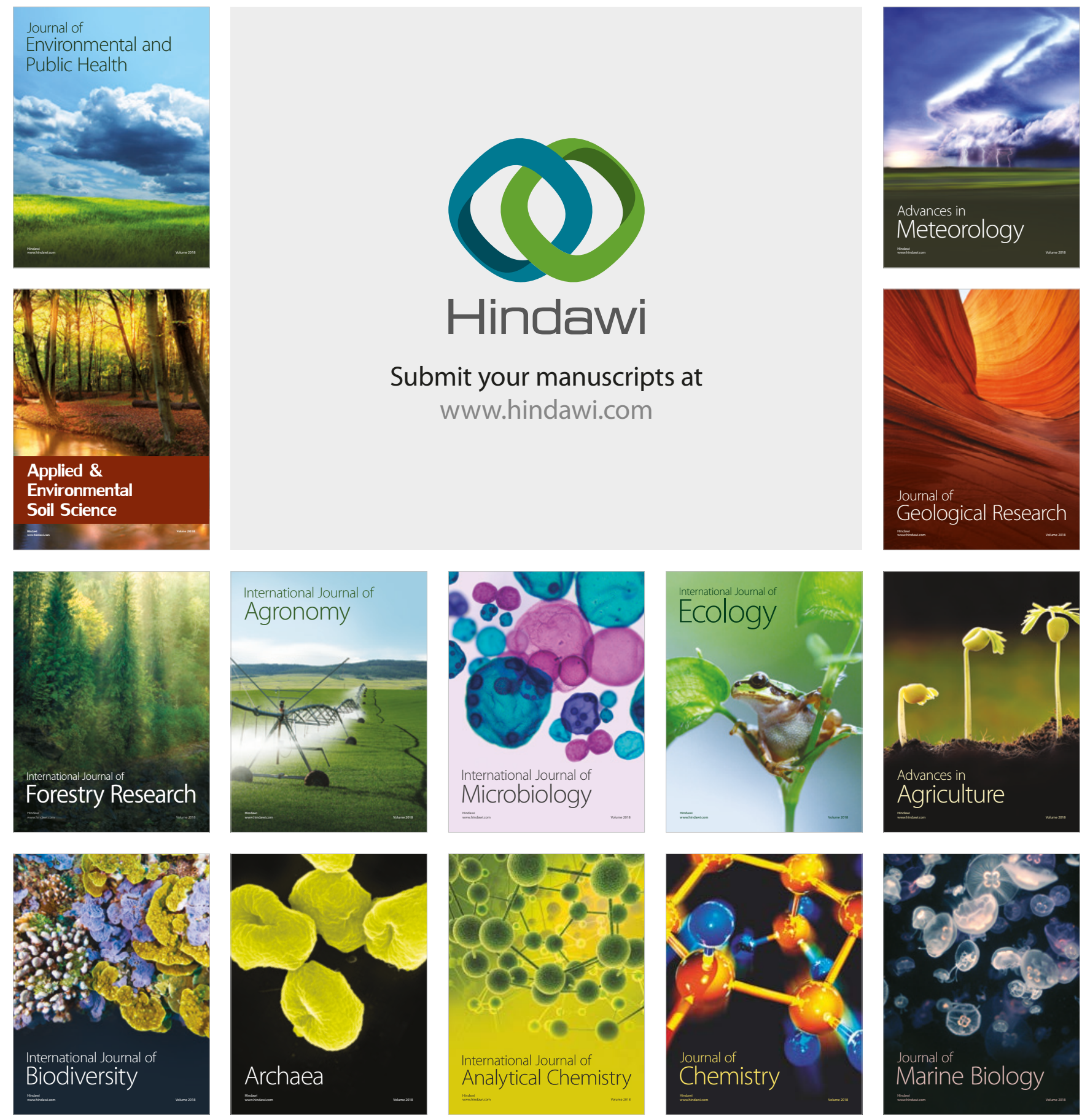